\title{
Screening for Non-communicable Diseases at a Walk-in Clinic in Trinidad and Tobago: A Time-motion Cross-sectional Study and Net Present Value Analysis
}

RG Maharaj' ${ }^{1}$ S Teelucksingh ${ }^{2}$, H Chow ${ }^{2}$, L De Freitas ${ }^{3}$

\begin{abstract}
Objective: To determine the feasibility of recommending a screening process for non-communicable diseases (NCDs) and their risk factors, as a national and regional model.

Methods: A cross-sectional, six-station process was carried out. It consisted of invitation and consent, history (personal and family history of NCDs), biometrics (waist circumference and body mass index), blood levels (lipids and glycosylated haemoglobin) and urinalysis (microalbuminuria), basic examinations (blood pressure, peripheral neuropathy, presence of acanthosis nigricans and visual acuity), and an exit interview. Net present value (NPV) calculations were carried out for very high-risk patients (those with a $>30 \%$ risk of a cardiovascular event (limb amputation) in the next 10 years) for two discount rates: $0.75 \%$ (United States of America) and 3.4\% (Trinidad and Tobago).

Results: A convenience sample of 514 walk-in patients (56.2\% recruitment rate) was screened (about 23 patients per day). The median time for a patient attending all stations was 21 minutes (range: 11-59 minutes). Of the six stations, the laboratory took the longest: median 10 minutes (range: 2-50 minutes). The entire project cost US\$20 439 (US\$39.76 per patient). Between one and seven very high-risk patients (three sub-groups of patients had this risk profile) were identified. The cost of identifying a very high-risk patient ranged from US\$2907 to US\$20 349. The NPV of identifying these high-risk patients ranged from-US\$6748.71 to US\$14 725 and was favourable for three of four monetary scenarios.

Conclusion: A six-station process to provide rapid screening of walk-in patients for NCDs was found to be feasible and provided monetary value in three of four scenarios in a Trinidad and Tobago setting.
\end{abstract}

Keywords: Ambulatory care, chronic disease, screening, Trinidad and Tobago

From: ${ }^{1}$ The Unit of Public Health and Primary Care, Faculty of Medical Sciences, The University of the West Indies, St Augustine, Trinidad and Tobago, West Indies, ${ }^{2}$ Department of Medicine, Faculty of Medical Sciences, The University of the West Indies, St Augustine, Trinidad and Tobago, West Indies and ${ }^{3}$ North Central Regional Health Authority, Trinidad and Tobago, West Indies.
Correspondence: Dr RG Maharaj, The Unit of Public Health and Primary Care, Faculty of Medical Sciences, The University of the West Indies, St Augustine, Trinidad and Tobago, West Indies. Email: rohan.maharaj@sta.uwi.edu 


\title{
Pruebas de detección de enfermedades no transmisibles en una clínica ambulatoria de Trinidad y Tobago: estudio transversal de tiempos y movimientos y análisis del valor actual neto
}

RG Maharaj ${ }^{1}$, S Teelucksingh ${ }^{2}, \mathrm{H} \mathrm{Chow}^{2}, \mathrm{~L}_{\text {De Freitas }}^{3}$

\begin{abstract}
RESUMEN
Objetivo: Determinar la viabilidad de recomendar un proceso de cribado de las enfermedades no transmisibles (ENT) y sus factores de riesgo, como modelo nacional y regional.

Métodos: Se realizó un proceso transversal de seis estaciones. El mismo consistió en invitación y consentimiento; historia (antecedentes personales y familiares de ENT); biometría (circunferencia de la cintura e índice de masa corporal); niveles sanguineos (lípidos y hemoglobina glicosilada); y análisis de orina (microalbuminuria); exámenes básicos (presión arterial, neuropatía periférica, presencia de acantosis nigricans y agudeza visual); y una entrevista de salida. Se realizaron cálculos del valor actual neto (VAN) para pacientes de muy alto riesgo - pacientes con riesgo de un 30\% de evento cardiovascular (amputación de extremidades) en los próximos 10 años - para dos tasas de descuento: 0.75\% (Estados Unidos de América) y $3.4 \%$ (Trinidad y Tobago).

Resultados: Una muestra de conveniencia de 514 pacientes ambulatorios (tasa de reclutamiento de 56.2\%) fue sometida a pruebas de detección (unos 23 pacientes por día). El tiempo promedio para que un paciente asistiera a todas las estaciones fue de 21 minutos (rango: 11-59 minutos). De las seis estaciones, el laboratorio tomó el tiempo más largo: un promedio de 10 minutos (rango: 2-50 minutos). El proyecto entero costó \$20 439 USD (39.76 USD por paciente). Entre uno y siete pacientes de muy alto riesgo (tres subgrupos de pacientes tenian este perfil de riesgo) fueron identificados. El costo de identificar a un paciente de muy alto riesgo osciló entre \$2907 USD y \$20 349 USD. El VAN de identificación de estos pacientes de alto riesgo fluctuó de \$6748.71 a \$14 725 USD, y fue favorable para tres de cuatro escenarios monetarios.

Conclusión: Se halló que un proceso de seis estaciones para pruebas de detección rápidas de ENT a pacientes ambulatorios, es factible y proporciona valor monetario en tres de cuatro escenarios en un contexto de Trinidad y Tobago.
\end{abstract}

Palabras clave: Atención ambulatoria, enfermedades crónicas, pruebas de detección, Trinidad y Tobago

West Indian Med J 2018; 67 (2): 123

\section{INTRODUCTION}

Non-communicable diseases (NCDs) and their associated risk factors were the main causes of mortality and disability in Latin America and the Caribbean (1). In 2008, the estimated mortality rate from NCDs in Trinidad and Tobago (T\&T) was $78 \%$, with cardiovascular disease and diabetes accounting for $34 \%$ and $14 \%$ of deaths, respectively (2). Further, compared with North America, the mortality rate for diabetes and cardiovascular disease in T\&T was $600 \%$ and $84 \%$ higher, respectively (3). In 2012, the PanAmerican STEPS risk factor survey conducted in T\&T reported that $21.1 \%$ were current smokers, $26.3 \%$ had high blood pressure, $30 \%$ were overweight and $25.7 \%$ obese, and $45 \%$ reported low physical activity (4).

In $T \& T$, healthcare services are provided via government-administered health centres. These centres provide a wide variety of free services including prenatal care, maternal and child health, vaccinations, well-baby care and NCD care. The evidence over the last 15 years suggested that we were not doing well when it came to NCDs. Several studies illustrate this. In 2001, a study of a primary care population revealed that $85 \%$ of diabetic patients had a glycosylated haemoglobin (HbA1c) of $>$ 
$7 \%, 31 \%$ had central obesity, $49 \%$ had a diastolic blood pressure (BP) of $>83 \mathrm{mmHg}$, and $40 \%$ had total cholesterol/high-density lipoprotein (HDL) ratios of $>6$ (5). In a 2002 audit of 826 diabetics, $72 \%$ had poor glycaemic control with random glucometer readings of $>200 \mathrm{mg} /$ $\mathrm{dL}$, and only $2 \%$ had $\mathrm{HbA} 1 \mathrm{c}$ levels done. Additionally, $67 \%$ of documented lipid profiles were abnormal. Only $1 \%$ of hypertensive diabetics had adequate control (6). In 2005, another study reported that there was an improvement in the increased use of tests among diabetics attending health offices and increased recording of diet and exercise advice. Yet, despite this, 'there were no changes in control of blood glucose, blood pressure or body weight' (7). In 2008, a review of the medical records of 646 diabetic patients to compare practice with regional guidelines found that waist circumference was never measured, lipid profiles were available in only $51 \%$, serum creatinine in $37.9 \%$ and $\mathrm{HbA} 1 \mathrm{c}$ in $<5 \%$ of patients. Patient advice on smoking, alcohol and exercise was recorded in only $12.2 \%$ of patients (8).

Other local studies have also recorded difficulty in achieving diabetic control. A prospective study at another clinic (9) published in 2011 focussed on 101 diabetic patients and produced a statistically significant reduction in $\mathrm{HbA} 1 \mathrm{c}$ from a mean of $9.44 \%$ to $7.96 \%$ over a threeyear period. This clinic used a patient-centred approach with a fixed physician providing care to a group of patients. However, even after three years, metabolic control was not achieved (on average).

According to the World Health Organization (WHO), deaths from NCDs were predicted to rise and to disproportionately affect the poorer populations and contribute to widening the health inequality gaps (10, 11). These trends affect national productivity and economic growth (12).

The WHO has suggested both population-wide and individual interventions to control NCDs (10). A proposed solution to combat NCDs is to invest in primary care, targeting the modifiable risk factors and screening for the common NCDs according to standard guidelines (13).

This pilot project investigated a time-motion and cost-analysis of a six-station screening circuit for NCDs. The overall aim was to determine the feasibility of recommending this as a national and regional model. The time-motion analysis sought to determine the rate of proceeding through all stations, the number of participants that could be screened in an hour, and the rate-limiting steps. The cost-analysis sought to determine the cost of producing and conducting the circuit and the cost of detecting patients of low, medium and high risks in a walk-in primary healthcare setting.

\section{SUBJECTS AND METHODS}

\section{The setting}

This cross-sectional study was carried out from July 1 to August 2, 2011 at the walk-in clinic of the Arima Health Facility, T\&T. This institution provided a mixture of community-based services, including an accident and emergency service, specialist services, chronic disease clinics and walk-in clinic services served by general practitioners. There was a heavy flow with several hundred patients attending every week.

\section{The staff}

Students who had finished secondary school and were enrolled in the government's on-the-job training (OJT) programme were recruited to assist with the project. These OJT workers and a nurse employed to supervise them underwent two days of training with the project supervisors and a laboratory technician experienced in the use of the point-of-care testing (POCT) machines. The nurse also conducted the consent process and the exit interview.

\section{The participants}

All ambulant patients who entered the clinic were eligible. Limited study staff meant that not all patients could be approached. Pregnant women, persons aged below 18 years, persons with diminished mental capacity, prisoners, non-English speakers, persons who refused to sign or initial the consent form, any person who presented with an emergency or was in pain or distress on attending the walk-in clinic were excluded from participating.

\section{The intervention}

The elements of the screening programme were developed based on the Caribbean Health Research Council's guidelines for the management of Type II diabetes (14). All of the risk factors highlighted in these guidelines, except physical inactivity, were assessed in the history. These guidelines also mention in their examination section conducting peripheral neuropathy checks and microalbumin testing, as available (14). Patients who were approached and signed the consent form were interviewed and basic demographics and risk factor evaluation based on personal and family history captured. Upon completion, participants then had their basic biometrics recorded: height and weight (using a 
Health o meter ${ }^{\circledR}$ scale and stadiometer, using standard population-based measurement techniques), waist circumference (using standard techniques) and BP (using an automated DynaMap ${ }^{\circledR}$ system). Following these biometrics, the CardioChek PA System ${ }^{\circledR}$ (15) was used to assess the lipid profile. Glycosylated haemoglobin and urine presence for microalbuminuria was carried out using the Siemens/Bayer DCA 2000+ Analyzer $^{\circledR}$ (16). The POCT underwent quality control twice: before the start of the project and again midway during the fourweek process. Next, a basic examination was carried out: staff used a Snellen chart and standard procedure for determining visual acuity and microfilament to test their peripheral sensation. The examiners also inquired about the presence of the slipping slipper sign (unknowingly losing a slipper while walking), a strong indicator of severe peripheral neuropathy (17). Finally, there was a review of the overall risk and further referral as necessary. On completion of the five steps, participants were provided with a summary of the findings plus an assessment of their risk which they could take to their personal doctor. Upon completing any of the stations, participants could move to any of the others, except the exit station which required the participant to have completed all previous stations so that recommendations could be made. Participants carried their individual reports with them to each station. Each report was created in duplicate: the copies were kept by researchers and the originals by the participants. Each station had one or two administrators with a stop watch who timed and documented the time for each stage (Fig. 1).

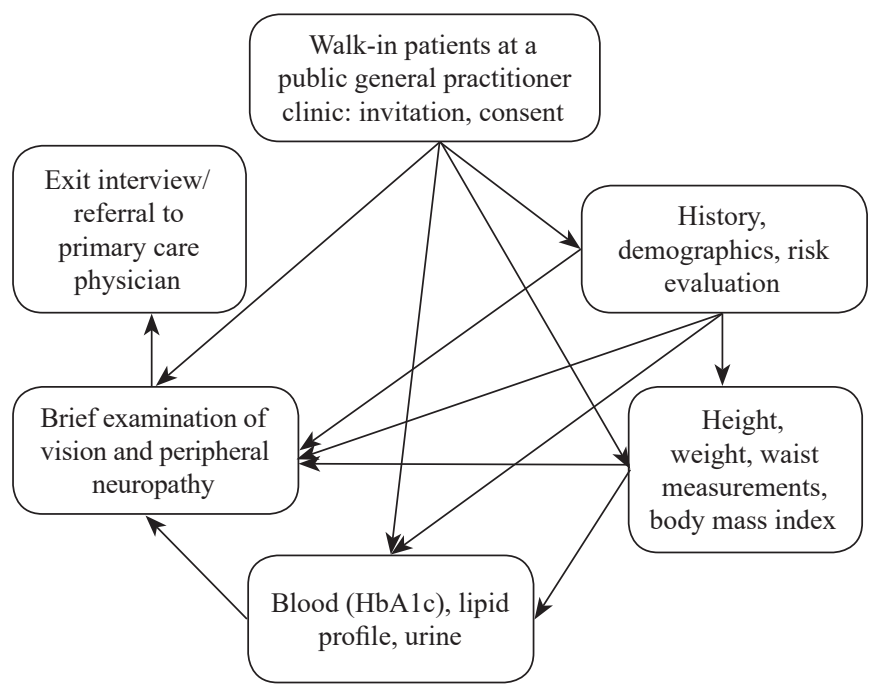

Fig. 1: Multi-phase (six stations) screening of walk-in patients at the Arima Health Facility, Trinidad and Tobago. Once consent was given, participants could attend any of the stations depending on availability. Upon completing all stations, they were eligible for an exit interview.

\section{Statistical analysis}

Descriptive statistics was used to present the time taken for each station, including the average time per station, the mean and range, and the demographics and metabolic parameters of the individual patients. Cross-tabulation was employed to obtain the breakdown of different variables by age groups and gender.

Using the Framingham Risk Scores from the Department of Health and Human Services, United States of America (USA), and the WHO/International Society of Hypertension (ISH) risk prediction charts, we calculated the individual risk of a cardiovascular event in the next 10 years $(18,19)$. The Framingham Risk Scores were calculated separately for males and females using the factors of age, blood cholesterol, blood HDL, tobacco use and systolic BP. The WHO/ISH risk prediction charts used gender, age, $\mathrm{HbAlc}$ levels, family history of early death in a first-degree relative, and smoking history. IBM SPSS (version 20.0) and Microsoft Excel were used to carry out these analyses.

\section{Analysis of net present values}

To assess the financial cost of investing in the screening programme, the net present value (NPV) was calculated. The NPV compares the anticipated costs of a programme with the projected earnings (in present dollars) over a period of time. It is the value in the present sum of money, in contrast to some future value it will have when it has been invested at compound interest. Generally, 'an investment with a positive NPV will be a profitable one and one with a negative NPV will result in a net loss' (20).

Firstly, using receipts from the suppliers, we determined the cost of conducting the entire project. This included the cost of POCT kits, the cost of human resources and other miscellaneous supplies; it did not include the cost of the space used.

To study the monetary value of screening, we compared the cost of finding very high-risk cases today, with the prospective cost of treating the least costly complication, namely, limb amputation in 10 years' time. That latter cost was conservatively estimated. Next, we used different discount rates (21) to calculate the NPV. The discount rate is an interest rate to determine the present values of future cash flows given the initial capital outlay. A software program (22) was used to determine the NPV.

\section{Ethical considerations}

Ethical approval was granted by the institutional review boards of the Faculty of Medical Sciences, The 
University of the West Indies and the North Central Regional Health Authority, T\&T.

\section{RESULTS}

\section{Participants}

During the one-month period of the study, 514 patients participated and 914 patients used the walk-in service at the health facility on the weekdays. All patients who attended the facility were invited, and no patient refused outright. However, because of scheduling and availability of clinic doctors, we were able to achieve a participation rate of $56.2 \%$. An average of 23 participants were screened daily. Participants were spread evenly among all age groups, with a fall-off among those aged over 60 years. Females constituted 362 (70.4\%) participants. Of the 514 participants, 31.5\% reported being Afro-Trinidadian, 22.6\% Indo-Trinidadian, 42.4\% mixed and $3.5 \%$ other. In terms of education, $41.4 \%$ completed secondary school examination, $29 \%$ primary school, $15 \%$ university, $8 \%$ vocational and technical and $6.2 \%$ post-primary education.

\section{History}

On history, 22 (4.2\%) participants reported being diabetic, $46(8.9 \%)$ hypertensive, $14(2.7 \%)$ heart disease, 52 (10.1\%) asthma, $50(9.7 \%)$ hypercholesterolaemia and 68 (13.2\%) were current smokers. Twenty-eight (5.4\%) participants reported that a male relative had died from cardiovascular disease before the age of 50 years and 32 $(6.2 \%)$ had a female relative who had died before the age of 65 years from a similar problem (Fig. 2).

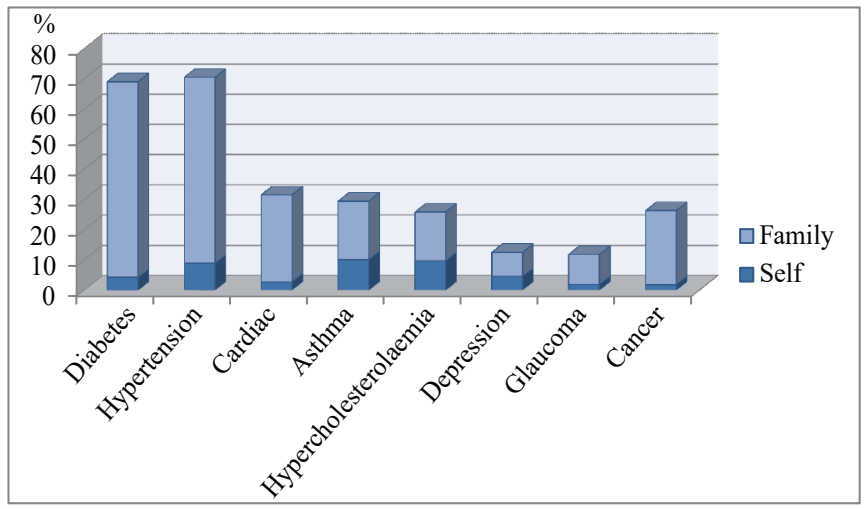

Fig. 2: Reported presence of non-communicable diseases in self and family.

\section{Overall risk}

Using WHO/ISH risk prediction charts (19), we defined four levels of risk: very high, medium, low-medium and low. The proportion of patients identified as being at very high risk (a greater than 30\% chance of a cardiovascular event in the next 10 years) ranged from $0.2 \%$ to $1.4 \%$. The proportion of patients defined as being at medium risk (a $20-30 \%$ chance of a cardiovascular event in the next 10 years) ranged from $3.7 \%$ to $7.2 \%$. No patients fell into the low-medium risk (a $10 \%$ to $<20 \%$ chance of a cardiovascular event in the next 10 years) category. The proportion of patients defined as being at low risk (a $<10 \%$ risk of a cardiovascular event in the next 10 years) ranged from $13.4 \%$ to $26.1 \%$ (Table 1 ).

Table 1: Costs of identifying very high, medium, low medium and low risk patients

\begin{tabular}{|c|c|c|}
\hline Risk definitions & $\begin{array}{c}\text { Number } \\
\text { of patients } \\
\text { identified } \\
(\%)\end{array}$ & $\begin{array}{c}\text { Cost of identifying } \\
\text { one patient, TT\$ } \\
\text { (US\$) }\end{array}$ \\
\hline \multicolumn{3}{|l|}{$\begin{array}{l}\text { Very high risk }(\sim 30 \%+\text { risk of a } \\
\text { cardiovascular disease }(C V D) \text { event } \\
\text { in next } 10 \text { years) }\end{array}$} \\
\hline $\begin{array}{l}\text { Males or females aged over } 50 \text { years } \\
\text { who had an HbA1c of }>6.5 \% \text { and } \\
\text { currently smoked }\end{array}$ & $7(1.4)$ & $\$ 18314(\$ 2907)$ \\
\hline $\begin{array}{l}\text { Males aged over } 50 \text { years who had an } \\
\text { HbA1c of }>6.5 \% \text { and a strong family } \\
\text { history of sudden cardiovascular death } \\
\text { before the age of } 50 \text { years in a first- } \\
\text { degree male relative }\end{array}$ & $1(0.2)$ & $\$ 128200(\$ 20349)$ \\
\hline $\begin{array}{l}\text { Males who smoked and had a strong } \\
\text { family history of sudden cardiovascular } \\
\text { death before the age of } 50 \text { years in a } \\
\text { first-degree male relative }\end{array}$ & $4(0.8)$ & $\$ 32050(\$ 5087)$ \\
\hline \multicolumn{3}{|l|}{$\begin{array}{l}\text { Medium risk (20-30\% risk of a CVD } \\
\text { event in next } 10 \text { years) }\end{array}$} \\
\hline $\begin{array}{l}\text { Males or females aged over } 50 \\
\text { years with an } \mathrm{HbA} 1 \mathrm{c} \text { of }>6.5 \% \text { and } \\
\text { cholesterol over } 200 \mathrm{mg} / \mathrm{dL}\end{array}$ & $19(3.7)$ & $\$ 6747(\$ 1071)$ \\
\hline $\begin{array}{l}\text { Males or females aged over } 50 \text { years } \\
\text { with an } \mathrm{HbA} 1 \mathrm{c} \text { of }>6.5 \% \text { and systolic } \\
\text { blood pressure of }>140 \mathrm{mmHg}\end{array}$ & $37(7.2)$ & $\$ 3464(\$ 550)$ \\
\hline $\begin{array}{l}\text { Low-medium risk }(10 \% \text { to }<20 \% \text { risk } \\
\text { of a CVD event in the next } 10 \text { years) }\end{array}$ & $0(0)$ & \\
\hline \multicolumn{3}{|l|}{$\begin{array}{l}\text { Low risk }(<10 \% \text { risk of a CVD event } \\
\text { in next } 10 \text { years) }\end{array}$} \\
\hline $\begin{array}{l}\text { An } \mathrm{HbA} 1 \mathrm{c} \text { of }>6.5 \% \text { in a patient not } \\
\text { known to be diabetic }\end{array}$ & $69(13.4)$ & $\$ 1857(\$ 295)$ \\
\hline Microalbuminuria & $134(26.1)$ & $\$ 956(\$ 152)$ \\
\hline
\end{tabular}

Using the Framingham Risk Score for males (18), $79.6 \%(\mathrm{n}=152)$ demonstrated $\mathrm{a}<10 \%$ risk of a cardiovascular event in 10 years, $28(18.4 \%)$ males had a $10-20 \%$ risk of an event in the next 10 years, and 3 male patients $(2 \%)$ had a $30 \%$ risk of an event in the next 10 years. No patients fell into the low-medium risk $(10 \%$ to $<20 \%)$ category. Among females, all $(100 \%)$ had a $\leq$ $10 \%$ risk of a cardiovascular event in the next 10 years when the Framingham Risk Score was applied (18). 


\section{Blood testing and urinalysis}

On blood testing and urinalysis, 21.6\% had elevated cholesterol levels ( $\geq 200 \mathrm{mg} / \mathrm{dL}$ ), $25.3 \%$ had triglyceride levels greater than $150 \mathrm{mg} / \mathrm{dL}, 59.8 \%$ had reduced HDL (measured here as $<60 \mathrm{mg} / \mathrm{dL}$ ), 167 (32.5\%) had HDL levels of $\leq 50 \mathrm{mg} / \mathrm{dL}$, and $65(12.6 \%)$ had HDL levels of $\leq 40 \mathrm{mg} / \mathrm{dL}$. Of the self-reported diabetics, $68 \%$ had an $\mathrm{HbAlc}$ of $>7 \%$; of these (with levels $>$ $7 \%$ ), $40 \%$ had HbA1c levels of $>10 \%$. A total of 69 (14\%) participants with no history of diabetes had an $\mathrm{HbA} 1 \mathrm{c}$ of $>6.5 \%$ and possibly represented newly identified diabetics. In total, $26.1 \%$ of the population tested had microalbuminuria. Of the self-reported diabetics, $72.7 \%(\mathrm{n}=22)$ had no microalbumin and six $(27.3 \%)$ had microalbuminuria. A total of $128(24.9 \%)$ patients without a history of diabetes demonstrated microalbuminuria.

\section{Biometric measurements}

On basic biometric measurements, 3.9\% of the participants were underweight, $24.5 \%$ had a normal body mass index (BMI), 37\% were overweight, and $34.8 \%$ were obese. Among males, $21.1 \%$ had a waist circumference greater than $102 \mathrm{~cm}$, and $27.6 \%$ of females had a waist circumference greater than $88 \mathrm{~cm}$. On measuring the systolic BP, $31.7 \%$ were normal, $32.1 \%$ had prehypertension (120-139 $\mathrm{mmHg}), 22.8 \%$ were at Stage 1 hypertension $(140-159 \mathrm{mmHg}$ ), and $13.4 \%$ were at Stage 2 hypertension $(160+\mathrm{mmHg})$. On measuring the diastolic BP, $66.9 \%$ were normal, $19.3 \%$ had prehypertension (80-89 $\mathrm{mmHg}$ ), 9.5\% were at Stage 1 hypertension (90-99 $\mathrm{mmHg}$ ), and $13.3 \%$ were at Stage 2 hypertension $(100+\mathrm{mmHg})$.

\section{Examination}

On examination, $21.6 \%$ of the patients were recognized to have visual impairment, $6.4 \%$ reported positive for the slipping slipper sign, $7.2 \%$ were positive for the loss of sensation by microfilament testing of the feet, and $32.7 \%$ were positive for any presence of acanthosis nigricans.

\section{Time-motion analysis}

The median time for completing the entire circuit was 21 minutes, with a maximum of 59 minutes and a minimum of 11 minutes. Of the six stations, the laboratory took the longest. The minimum time taken at this station was 2 minutes, the median 10 minutes and the maximum 50 minutes. The median time for invitation and consent was five minutes, history two minutes, biometrics three minutes, basic examinations four minutes and exit interview three minutes. Figure 1 illustrates that participants could move among all the stations once consent was obtained and as long as the exit station was the final one. Figure 3 provides the box plot distribution of the times for each of the six stations.

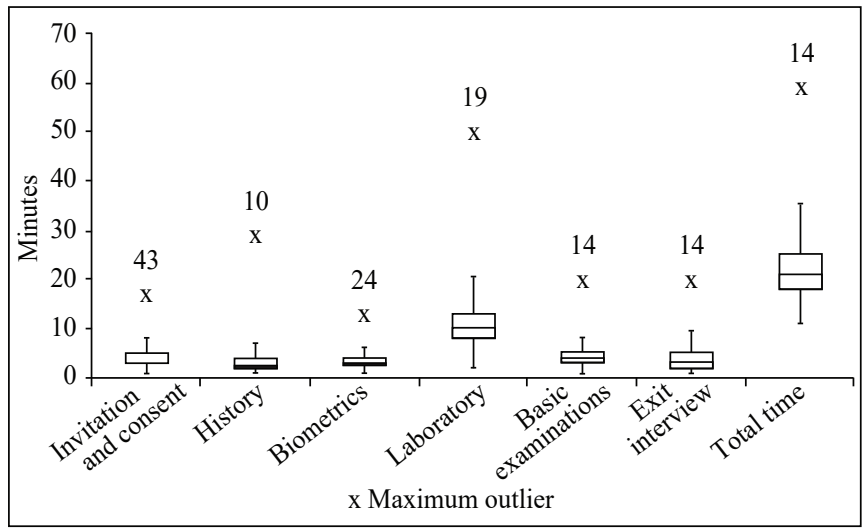

Fig. 3: Box plots of the time (minutes) required for completion of each station and their combined time. For simplicity, the number of outliers was shown as a number, and the maximum outlier was illustrated as an ' $x$ '. Minimum outliers did not show up as the lower end of the whiskers of the box plot was close to the zero on the y-axis.

\section{Monetary analysis}

The cost of conducting the entire project was US\$20 439. This included the cost of POCT kits, the cost of human resources and other miscellaneous supplies; it did not include the cost of the space used.

To study the monetary value of screening, we compared the cost of finding very high-risk cases today (we used two different scenarios: a patient aged over 50 years who had an elevated HbAlc and smoked, with a cost per case of US\$2907; and a male patient aged over 50 years who had an $\mathrm{HbA} 1 \mathrm{c}$ of $>6.5 \%$ and a strong family history of sudden cardiovascular death before the age of 50 years in a first-degree male relative, with a cost of US\$20 349 per case), with the prospective cost of treating the least costly complication, namely, limb amputation in 10 years' time. Table 1 gives further overall risks and cost descriptions.

If the cost of limb amputation was conservatively estimated at US\$19 000 and when we used different discount rates (USA discount rate: $0.75 \%$; T\&T discount rate: $3.4 \%$ ), three of four scenarios were favourable. The most favourable scenario was for patients aged over 50 years who had an HbA1c of $>6.5 \%$ and smoked. With an initial cost of US\$2907 to identify this patient and a discount rate of $3.4 \%$, the potential NPV was US\$14 725 (Table 2). 
Table 2: Net present values (NPV) for two patient scenarios but differing initial costs and discount rates

\begin{tabular}{lcccc}
\hline Monetary scenario & $1^{\#}$ & $2^{\# \#}$ & $3^{\#}$ & $4^{\# \#}$ \\
\hline Patient risk scenario & $1^{*}$ & $1^{*}$ & $2^{* *}$ & $2^{* *}$ \\
\hline $\begin{array}{l}\text { Approximate direct cost } \\
\text { of amputation in 10 }\end{array}$ & $\$ 19000$ & $\$ 19000$ & $\$ 19000$ & $\$ 19000$ \\
years (US\$) & & & & \\
$\begin{array}{l}\text { Discount rate } \\
\text { Initial cost to identifying }\end{array}$ & $3.4 \%^{\#}$ & $0.75 \% \%^{\# \#}$ & $3.4 \%^{\#}$ & $0.75 \% \%^{\# \#}$ \\
one patient (US\$) & & $\$ 2907$ & $\$ 20349$ & $\$ 20349$ \\
Time span (years) & 10 & 10 & 10 & 10 \\
$\begin{array}{l}\text { Present value (US\$) } \\
\text { NPV (US\$) }\end{array}$ & $\$ 13600.29$ & $\$ 17632$ & $\$ 13600.29$ & $\$ 21808$ \\
\hline
\end{tabular}

* Patient risk scenario 1: males or females aged over 50 years who had an $\mathrm{HbA} 1 \mathrm{c}$ of $>6.5 \%$ and currently smoked.

** Patient risk scenario 2: males aged over 50 years who had an $\mathrm{HbA} 1 \mathrm{c}$ of $>$ $6.5 \%$ and a strong family history of sudden cardiovascular death before the age of 50 years in a first-degree male relative.

\# Trinidad and Tobago discount rate at the time of conducting the NPV analysis $=3.4 \%$.

\# US discount rate at the time of conducting the NPV analysis $=0.75 \%$.

\section{DISCUSSION}

We conducted a six-station cross-sectional study over a one-month period, with a recruitment rate of approximately 56\%. Each station completed one step in screening for NCD risk factors among non-emergent walk-in patients at the Arima Health Facility in T\&T. We identified one very high-risk patient for between US\$3000 and US\$20 000 spent, depending on how the risk was determined. The median time for a patient attending all stations was 21 minutes, with a maximum of 59 minutes and a minimum of 11 minutes. A NPV analysis revealed that three of four monetary scenarios were favourable.

Most health centres in T\&T use hospital-based testing for blood, which means that results are not available for immediate physician management decisions to be made when patients are being seen. Many patients report that they are seen with reports from their previous visits, three months prior. To address these, POCT, as used in this study, may be used in local primary care settings. Point-of-care testing is defined as any test taken on-site that allows the test result to be used to make immediate clinical decisions regarding patient care $(23,24)$. The types of available POCT also vary from basic tests to more advanced tests such as HbA1c (25). Point-of-care testing is not new and has been well studied (26-34). Relatively few studies have examined its use in primary care settings $(27,28,30$, 32 ), and none has been published from the Caribbean. Several studies have examined the clinical effectiveness, diagnostic accuracy, patient satisfaction and cost-effectiveness of POCT $(26,27)$, improved compliance $(28,29)$, stronger doctor-patient relationships (30), optimal glycaemic control (31), and equivocal cost $(33,34)$.

In the T\&T setting where laboratory services have traditionally been centralized and under-funded, POCT would be convenient for patients and useful for physicians to make clinical decisions in the health centre setting.

We could find no cost comparison data for NCDs in T\&T. Regionally, cost analysis papers are more panoramic in nature (35). As such, we used our knowledge of the health system to estimate the cost of having an amputation in $\mathrm{T} \& \mathrm{~T}$.

This study illustrated that with a small investment, retired staff, and pre-university students with a twoday training programme, screening for NCDs and their risk factors could be readily implemented in a Caribbean setting. This model is easily reproducible and can be implemented in other parts of T\&T and the Caribbean region.

There were several challenges to conducting this study. For example, the processes described ran concurrently with clinic activities. While attendees were keen on participating (POCT was not otherwise available at the centre when this study was conducted), many could not be accommodated. This led to the low recruiting rate. Occasionally, patients had to leave the circuit to see the physician and return to complete the evaluation. This led to disruptions in the clinic flow and artificial extension of the circuit. The automated machines also malfunctioned on one occasion.

Analyses of NPVs had many weaknesses, such as not taking into account the loss of income, time taken off work to care for a loved one, and incidental costs to the health system. The savings calculated here were well below what a more extensive analysis would provide.

The participants in this study may not be fully representative of the overall $\mathrm{T} \& \mathrm{~T}$ population. This population had a larger proportion of Afro-Trinidadians and those of mixed ethnicity than Indo-Trinidadians, compared to those in the national population. This was expected in this particular catchment area. Of note, only $4.2 \%$ of the participants self-reported as being diabetic. In the recent PanAmerican STEPS, 7.9\% of the participants reported being diagnosed with diabetes (4). This population had similar proportions of participants $(21.6 \%)$ with elevated total cholesterol, compared to the PanAmerican STEPS survey (23.5\%). However, those with elevated triglycerides in the PanAmerican 
STEPS were much higher (49.7\% versus $25.3 \%)$. A comparison of BMI revealed that the proportion of those being overweight or obese in the STEPS survey was reported as $55.7 \%$, while the proportion in this study was $71.8 \%$.

\section{Future work}

This study provided an idea of the direct cost of implementing a wide-scale screening programme. What it did not provide was the indirect costs of confirming the results detected with these instruments and staff, and the additional cost to the patient and the system to seek further medical care. Similarly, we were unaware of the savings that may be generated through the early detection of patients with abnormalities on testing.

An interesting comparison was the difference in risk stratification based on the WHO and the Framingham models. There was a clear difference in parameters entered in the models with the WHO using HbAlc levels, which the Framingham did not. The WHO scores identified seven patients as having a $>30 \%$ risk of a cardiovascular event in the next 10 years; Framingham identified only three. Using the Framingham score, all women were determined as having a $<10 \%$ risk of a cardiovascular event in the next 10 years. There is a gap in our knowledge in the West Indies on which risk model is better suited for our population. These are all questions for further study.

\section{CONCLUSION}

A six-station screening process in conjunction with simple, easily learnt history, biometric measurements, POCT and basic examinations was found to be practical for the screening of walk-in patients for NCDs in a T\&T setting. Our brief analysis suggested that the process might be economically feasible, but future study would be required to ascertain if this was truly so.

\section{ACKNOWLEDGEMENTS}

The authors would like to acknowledge financial support from the Inter-American Development Bank's Regional Public Goods grant ATN/OC-10756-RG and assistance in the data collection by the County Medical Officers, the Clinical Research Nurse and OJT trainees, Government of the Republic of T\&T.

\section{AUTHORS' NOTE}

The authors declare that they have no competing interests.

\section{REFERENCES}

1. Glassman A, Gaziano TA, Bouillon Buendia CP, Guanais de Aguiar FC. Confronting the chronic disease burden in Latin America and the Caribbean. Health Aff (Millwood) 2010; 29: 2142-8.

2. World Health Organization. Non-communicable diseases country profiles 2011. Available at: http://whqlibdoc.who.int/publications/2011/9789241502283 eng.pdf.

3. Samuels T, Fraser H. Caribbean wellness day: mobilising a region for non-communicable disease prevention and control. Rev Panam Salud Publica 2010; 28: 472-9.

4. Ministry of Health, Government of the Republic of Trinidad and Tobago. Trinidad and Tobago - chronic non-communicable diseases, risk factor survey [Pan American STEPS], final report, 2012. Available at: www. health.gov.tt/downloads/DownloadDetails.aspx?id=314.

5. Ezenwaka CE, Offiah NV. Differences in glycemic control and cardiovascular risk in primary care patients with type 2 diabetes in West Indies. Clin Exp Med 2001; 1: 91-8.

6. Patel S, Hosein PJ, Poon-King I. A primary care audit of diabetes mellitus in central Trinidad. West Indian Med J 2004; 53(Suppl 2): 52.

7. Mahabir D, Gulliford MC. Changing patterns of primary care for diabetes in Trinidad and Tobago over 10 years. Diabet Med 2005; 22: 619-24.

8. Ali I, Gooding R, Ragbir M, Samaroo K, Hinds A, Pinto Pereira LM. Does the management of Type 2 diabetes in primary care meet the Diabetes management guidelines of the Caribbean Health Research Council in St George West County, Trinidad and Tobago. West Indian Med J 2008; 57(Suppl 2): 26.

9. Babwah T. Improving glycaemic control in patients attending a Trinidad Health Centre: a three-year quality improvement project. Qual Prim Care 2011; 19: 335-9.

10. World Health Organization. Burden, mortality, morbidity and risk factors. In: WHO. Global status report on non-communicable diseases 2010. Geneva: WHO. Available at: www.who.int/nmh/publications/ ncd_report_chapter1.pdf.

11. World Health Organization. Prevention and control of non-communicable diseases: implementation of the global strategy. Geneva: WHO. Available at: http://apps.who.int/gb/ebwha/pdf_files/A61/A61_8-en. pdf.

12. World Health Organization. Preventing chronic diseases - a vital investment. Geneva: WHO. Available at: www.who.int/chp/chronic disease_report/contents/foreword.pdf.

13. Maher F, Ford N. Action on non-communicable diseases: balancing priorities for prevention and care. Bulletin of the World Health Organization. Geneva: WHO. Available at: www.who.int/bulletin/ volumes/89/8/11-091967/en.

14. Caribbean Health Research Council. Managing diabetes in primary care in the Caribbean. Available at: http://carpha.org/downloads/ Diabetes\%20Guidelines.pdf.

15. PolymerTechnology Systems Inc. CardioChek ${ }^{\circledR}$ PATest System, introduction. Available at: www.ptsdiagnostics.com/uploads/2/6/2/8/26289179/ ps-002461 en rev. 4 user guide cardiochek pa.pdf.

16. Siemens/Bayer DCA $2000+$ Analyzer. Available at: www.gmi-inc.com/ siemens-bayer-dca-2000-analyzer.html.

17. Teelucksingh S, Ramdass MJ, Charran A, Mungalsingh C, Seemungal T, Naraynsingh V. The slipping slipper sign: a marker of severe peripheral diabetic neuropathy and foot sepsis. Postgrad Med J 2009; 85: 288-91.

18. US Department of Health and Human Services, Public Health Service, National Institutes of Health, National Heart, Lung, and Blood Institute. ATP III guidelines at-a-glance quick desk reference. NIH Publication No. 01-3305. May 2001. Available at: www.nhlbi.nih.gov/files/docs/ guidelines/atglance.pdf.

19. World Health Organization. WHO/ISH risk prediction charts for 14 WHO epidemiological sub-regions. Available at: http://ish-world.com/ downloads/activities/colour_charts_24_Aug_07.pdf.

20. Investopedia. Net present value - NPV. Available at: www.investopedia. com/terms/n/npv.asp\#ixzz3zgPNV8a8.

21. Investopedia. Discount rate. Available at: www.investopedia.com/ terms/d/discountrate.asp. 
22. Investopedia. Net present value calculator. Available at: www.investopedia.com/calculator/netpresentvalue.aspx.

23. Gialamas A, St John A, Laurence CO, Bubner TK, PoCT Management Committee. Point-of-care testing for patients with diabetes, hyperlipidaemia or coagulation disorders in the general practice setting: a systematic review. Fam Pract 2010; 27: 17-24.

24. Price C. Point of care testing. BMJ 2001; 322: 1285.

25. Fitzmaurice D. Near patient testing in primary care. Br J Gen Pract 2004; 54: 650-1.

26. Tomonaga Y, Gutzwiller F, Lüscher TF, Riesen WF, Hug M, Diemand A et al. Diagnostic accuracy of POCT for acute coronary syndrome, heart failure and thromboembolic events in primary care: a cluster-randomised controlled trial. BMC Fam Pract 2011; 12: 12.

27. Bubner TK, Laurence CO, Gialamas A, Yelland LN, Ryan P, Willson $\mathrm{KJ}$ et al. Effectiveness of point-of-care testing for therapeutic control of chronic conditions: results from the PoCT in General Practice Trial. Med J Aust 2009; 190: 624-6.

28. Gialamas A, Yelland LN, Ryan P, Willson K, Laurence CO, Bubner TK et al. Does point-of-care testing lead to the same or better adherence to medication? A randomised controlled trial: the PoCT in General Practice trial. Med J Aust 2009; 191: 487-91.

29. Shephard A, Shephard M, Halls H, Corso O, Mathew T. Innovative use of point-of-care testing for chronic kidney disease screening. Point of Care 2011; 10: 98-101.
30. Laurence CO, Gialamas A, Bubner T, Yelland L, Willson K, Ryan P et al. Patient satisfaction with point-of-care testing in general practice. $\mathrm{Br} \mathrm{J}$ Gen Pract 2010; 60: e98-104.

31. Shephard MD, Mazzachi BC, Shephard AK, McLaughlin KJ, Denner B, Barnes G. The impact of point of care testing on diabetes services along Victoria's Mallee Track: results of a community-based diabetes risk assessment and management program. Rural Remote Health 2005; 5: 371-86.

32. Stone MA, Burden AC, Burden M, Baker R, Khunti K. Near patient testing for glycated haemoglobin in people with Type 2 diabetes mellitus managed in primary care: acceptability and satisfaction. Diabet Med 2007; 24: 792-5.

33. Laurence CO, Moss JR, Briggs NE, Beilby JJ, PoCT Trial Management Group. The cost-effectiveness of point of care testing in a general practice setting: results from a randomised controlled trial. BMC Health Serv Res 2010; 10: 165.

34. Khunti K, Stone MA, Burden AC, Turner D, Raymond NT, Burden M et al. Randomised controlled trial of near-patient testing for glycated haemoglobin in people with type 2 diabetes mellitus. Br J Gen Pract 2006; 56: $511-7$.

35. Barceló A, Aedo C, Rajpathak S, Robles S. The cost of diabetes in Latin America and the Caribbean. Bull World Health Organ 2003; 81: 19-27. 